\title{
INTERVENÇÕES ESTATAIS: TERRAS INDÍGENAS, AGENDA AMBIENTAL E REPRESENTAÇÃO INDÍGENA
}

\section{Rodrigo Paranhos Faleiro - Doutorando PPG/CEPPAC, Universidade de Brasília}

\section{INTRODUÇÃO}

Nos últimos cinquenta anos, entre as diversas formas de intervenção estatal praticada por Estados nacionais na vida dos povos indígenas, o reconhecimento de territorialidades com fins ambientais e étnicos em uma mesma área tem sido ato comum de governos de países das Américas. Tais superposições de categorias jurídicas em um mesmo território tendem a fortalecer o poder de atuação das agências ambientais em territórios indígenas e a diminuir a autonomia indígena, implicando assim novos arranjos de poder e mais tensões entre indígenas e Estados nacionais.

Todavia, ao traçarmos uma breve revisão do processo histórico de territorialização das áreas tradicionalmente ocupadas por índios no Brasil, observamos ser esta forma de intervenção apenas mais um episódio de controle da vida dos indígenas. Porém, diferente das intervenções realizadas por motivações meramente econômicas, neste novo episódio são apresentadas justificativas apoiadas em agendas internacionais de meio ambiente, direitos humanos etc., que, por sua vez, nos ofertam um novo cenário analítico.

Apesar de considerarmos ser a sobreposição uma intervenção nos territórios indígenas do Brasil, quando analisamos esses casos em outros países latino-americanos onde não existem as mesmas garantias legais para o índio ter acesso ao seu território tradicional, algumas vezes, as unidades de conservação acabam sendo a única opção para garantir a permanência desses povos em seus territórios. Evidentemente, em alguns casos, isso ocorre por esses países entenderem que a presença de povos indígenas seria compatível com as unidades de conservação. Leitura que nos impõem outras questões. Independente disto, neste trabalho procuro discutir alguns aspectos da intervenção estatal que, muitas vezes, são evitados por questões ideológicas. Com isso, espero ofertar uma reflexão desmistificadora para o tema com a finalidade de podermos avançar em debates acerca dos territórios indígenas e das agendas ambientais.

Para tanto, parto dos dados coletados ao longo dos últimos vinte anos, quando estive trabalhando com conflitos entre terras indígenas e unidades de conservação no Brasil e América Latina. Durante este período, mantive contato com muitos atores citados ao longo do texto, participei da negociação dos conflitos que caracterizaram os bastidores das comemorações do "Brasil: 500 anos", acompanhei outros casos no Brasil-Illha do Bananal no Goiás, Illha do Superagui no Paraná, Serra do Divisor no Acre, Raposa Serra do Sol em Roraima, etc. --, participei - ora como representante da pasta ambiental, ora como coordenador - da elaboração do Projeto "Catalisando a contribuição das Terras Indígenas para a Conservação dos ecossistemas florestais brasileiros", proposto pelos índios ao Global Environment Facility (GEF), e participei de debates latino-americanos do tema na REDPARQUES e UICN. Lugar de observação que, uma 
vez problematizado pelo “olhar” acadêmico, possibilitaram tecer a análise que apresento neste trabalho. Investimento que, longe do modelo clássico de comparação focado em dois casos, propõem um exercício de estranhamento das condições adversas que as intervenções estatais suscitaram no tempo em relação a algumas políticas de gestão territorial.

\section{INTERVENÇÃO ESTATAL: UMA PRÁTICA HISTÓRICA}

Apesar da dificuldade em propor uma definição do que seria o Estado contemporâneo hoje, Gozzi (1998) aponta algumas características típicas desse ente. Para ele, o processo histórico caracterizado pela interação do Estado com a sociedade, em seu sentido mais amplo, gerou tantas singularidades que dificilmente poderíamos estabelecer um conceito definitivo de Estado. Pois, desde o monopólio da força de Hobbes, o poder legal-racional weberiano, o Estado de direito, a leitura atual do tema pelos marxistas, o estado fiscal, o estado liberal etc. - tendências conceituais descritas pelo autor -, haveria possíveis conceitualizações que, sem qualquer restrição, mantiveram diálogo com contextos sociais bastante diversificados. Esses contextos impuseram e continuam impondo demandas às elites políticas de cada lugar que, por sua vez, buscam respondê-las com adaptações de modelos, experiências e iniciativas, resultando em muitas variações daquilo que, em um curto espaço de tempo, dificilmente poderia ser unificado em um só conceito de Estado.

Embora seja árdua a tarefa de definir o Estado, ainda hoje persiste o consenso estabelecido pela Convenção de Montevidéu, realizada em 1933, a respeito das condições necessárias para ser reconhecido um país. De acordo com a Convenção, um país deve ter uma população fixa, um território definido, um governo, ser reconhecido pelos seus pares e ter a capacidade de relacionar-se com os demais países. Tais definições impõem ao país uma configuração de exercício do poder estatal que, por sua vez, nos oferta um conceito pragmático daquilo que, minimamente, seria um Estado na ordem mundial atual. Logo, considerando ser o Estado o ente que abriga o governo e que administra o país, podemos assumir ser inerente à existência do primeiro a capacidade de exercer o domínio sobre os habitantes e o território que integram o país. Tema este que pretendo explorar, já que as diferentes definições do que seria o "Estado" não caberiam neste trabalho e sim, o que este ente produz sobre as coletividades que denominamos indígenas. Tal assertiva incorpora o Estado menos por seu caráter pretensamente unívoco, como já exploramos em outros trabalhos, e mais pelo dinamismo ideológico das equipes que nele atuam e o personificam. Se estivermos corretos, temas como a nacionalidade dos cidadãos e a soberania sobre seu território seria um recorte analítico mais produtivo para entendermos as relações estabelecidas entre o Estado e os povos indígenas.

Segundo Tivey (1981), o Estado nacional moderno tem essa preocupação com o exercício do domínio de seus cidadãos e seu território desde a sua origem. Pois, até o Século XVII, muitos governantes não exerciam o domínio de suas posses e, portanto, dos habitantes dessas áreas. Por isso, mediante o uso da força, muitos deles trataram de estabelecer esse domínio territorial com a consequente vinculação dos habitantes a uma ideia de nação. Nascia aí o Estado nacional. A partir do estabelecimento dos Estados nacionais também nasceram muitos países que hoje reconhecemos como nações mais antigas - notadamente, os países europeus - e que, naquele momento, não passavam de comunidades que viviam em uma área mais ou menos próxima. 
Melatti (1987) e Ribeiro (1970) nos descrevem um exercício de dominação estatal semelhante nas terras brasileiras. Pois, se inicialmente, o conquistador europeu tratou de exercer essa dominação através da força armada, do comércio e da conversão religiosa. Mais tarde, uma vez liberta a colônia, os governantes dos novos países deram continuidade a afirmação de sua soberania através da constituição do Estado nacional. Para Lima (1995), o Estado brasileiro desenvolveu no Século XX uma eficaz estratégia de conversão de áreas e habitantes em, respectivamente, território nacional e cidadãos brasileiros. Para isso, era estabelecida a presença estatal no território considerado nacional e, com isso, estimulado o reconhecimento do jugo estatal pelos habitantes dessas áreas. Tal combinação teria como alicerce a assistência pretensamente prestada pelo Estado - incluindo aí a tutela - e como objetivo, inerente ao empreendimento estatal, a vinculação econômica desses povos aos interesses nacionais. Desse modo, como diz o autor, dar-se-ia a disciplinarização do campo pretensamente pensado enquanto um só Brasil.

Para Lima (1995), ao disciplinarizar o campo pelo emprego da tutela sobre o indígena, o Estado brasileiro desenvolveria uma forma disfarçada de controle desses povos. Como pudemos verificar em outro trabalho (vide PARANHOS FALEIRO, 2012), essa assistência estatal seria uma forma de assimilação e integração desses povos à sociedade brasileira. A política de assimilação do indígena praticada no início do Século XX seria reformulada nos anos setenta, dentro do esforço de dar resposta às denúncias de abuso e corrupção que teriam sido praticados pelos dirigentes do Serviço de Proteção ao Índio (RIBEIRO, 1970). Para tanto, no lugar do Serviço seria criada a Fundação Nacional do Índio (FUNAI) que, não sendo mais uma agência formalmente assimilacionista, desenvolveria uma política de integração dos indígenas à sociedade brasileira (LIMA, 1995). Política esta que seria reformulada apenas com a homologação da Constituição Federal em 1988.

O amadurecimento da política indigenista brasileira nos anos oitenta poderia ser interpretado como um desdobramento natural do processo de controle social do poder Estatal no contexto de redemocratização que era vivido na época. Segundo nos confidenciou Márcio Santilli, indigenista, ex-presidente da FUNAI e constituinte de 1988, havia uma preocupação do legislador em garantir direitos aos indígenas - e a outros grupos sociais também - até então negligenciados pelo Brasil.Afinal, comodemonstra Melatti(1987), independente de ser praticadapelo empreendimento colonial, pela Igreja ou pelo Estado, a política indigenista brasileira geralmente serviu aos interesses não indígenas. Segundo Lima (1995), a política indigenista do Serviço de Proteção ao Índio era mais nacionalizante e economicista que, necessariamente, benevolente para com o indígena. Pois, nas áreas aonde os índios eram aguerridos contra as frentes de colonização, a ação estatal consistia em pacificar e submeter o grupo arredio, redesenhar seu território em áreas menores, destinar às terras restantes para o estabelecimento de colonos não indígenas e em capacitar os índios a serem colonos. Sem sombra de dúvida, o único altruísmo estatal da política indigenista da época seria a concessão de áreas agricultáveis para os não índios que, por sua vez, passariam a ocupar os recém-expropriados territórios indígenas.

Já a política de integração do indígena desenvolvida pela FUNAI a partir dos anos setenta do século XX seria explicitamente caracterizada pelo reconhecimento do território, a assistência - alimentação, saúde, educação, etc. - e o alcance de diferentes grupos indígenas. Pois, até aquele momento, apenas as demandas de terras e de controle dos índios arredios elencados pela opinião pública monopolizavam o Serviço de Proteção ao Índio (SPI) (LIMA, 1995). 
Porém, se a FUNAI ampliou o público a ser atendido, apenas com a Constituição Federal homologada em 1988, ela receberia o mandato de impor uma política mais orientada para os interesses indígenas que os nacionais - onde terras tradicionalmente ocupadas seriam demarcadas e não desocupadas segundo os interesses não indígenas; a condição de isolamento de alguns grupos seria preservada e não mais contatada para evitar confrontos com os colonos; e o uso exclusivo dos recursos naturais da terra indígena seguiria os padrões da etnia e não aqueles convenientes para o desenvolvimento do país. (PARANHOS FALEIRO, 2005).

Apesar desse amadurecimento legal da política indigenista brasileira, ainda hoje, podem ser flagradas as ambiguidades do indigenismo brasileiro. Melatti (1987) apresenta uma coroa portuguesa bem intencionada nas normas editadas para proteção dos indígenas e, ao mesmo tempo, conivente com o emprego da força contra aquelas etnias que obstruíam o empreendimento colonial. Apesar da distância do período colonial e o Século XXI, em outro trabalho (PARANHOS FALEIRO, 2009) pudemos denunciar como a assistência estatal continua impregnada de tentativas de controle dos povos indígenas por equipes que atuam em nome da agência indigenista. Naquele trabalho, expusemos que existem espaços institucionais na FUNAI que abrigam projetos ideológicos que obstruem interesses legítimos dos indígenas e que, por meio deles, alçam pessoas a cargos mais prestigiados. No entanto, se observamos na pessoalidade de funcionários da agência indigenista uma ideologia desenvolvimentista ou personalista que classifica o indígena como um artefato fadado à extinção ou como meio de auto promover-se, sem dúvida alguma, a grande maioria dos funcionários está realmente engajada na defesa dos interesses indígenas. Por este motivo, seria a princípio mais favorável a uma política executada por funcionários engajados em prol dos interesses genuinamente indígenas do que uma gestão pública impessoal aonde nada acontece. Tema que retomaremos adiante.

\section{TEMPOS DE GLOBALIZAÇÃO: AS AGENDAS INTERNACIONAIS}

No final do Século XX, as mudanças na política indigenista brasileira seriam acompanhadas pelas iniciativas internacionais em prol do estabelecimento de uma nova ordem mundial. Sob os interesses da Guerra Fria, após a Segunda Guerra Mundial houve um esforço dos países desenvolvidos em estabelecer instituições internacionais que deveriam diminuir - e controlar - as crises internacionais em potencial - ou aquelas que thes eram convenientes. Embora pudéssemos aprofundar nossas considerações sobre o papel dessas instituições naquele contexto polarizado, declino dessa possibilidade para reforçar apenas que, após a dissolução da União das Repúblicas Socialistas Soviéticas (URSS) e o fim da Guerra Fria, esses organismos internacionais ganharam mais força nos cenários internacionais e, com poucas exceções, passaram a influenciar propositivamente as políticas nacionais.

Neste contexto, convém destacar a importância da Reunião do Rio de Janeiro em 1992 que, invertendo a posição defendida pelo Brasil na Conferência das Nações Unidas sobre o Meio Ambiente Humano, realizada em 1972 em Estocolmo na Suécia, impulsionou a agenda ambiental brasileira nas últimas duas décadas. Pois, se outrora esta agenda havia sido interpretada como uma intervenção dos países ricos nos projetos de desenvolvimento dos países subdesenvolvidos e dos países em desenvolvimento, em 1992, ela seria reinterpretada a partir das preocupações internacionais com a sustentabilidade do planeta. Enquanto o Ocidente estava repleto de esperanças em relação ao 
futuro - fim da guerra fria, redemocratização dos países soviéticos e latino-americanos etc. - , em termos pragmáticos, parte da diplomacia envolvida na Reunião do Rio negociava a transferência de tecnologias e recursos financeiros dos países ricos para países que detinham áreas naturais e que, em troca dessa transferência, assumiriam o compromisso com a conservação ambiental (PARANHOS FALEIRO, 2005).

Embora a política ambiental brasileira tenha sido impulsionada pelas agendas internacionais de meio ambiente, isso não impossibilitou que propostas tipicamente brasileiras ganhassem espaço. Entre as diversas iniciativas nacionais, alcançou destaque internacional a relativização de categorias de unidades de conservação dedicadas exclusivamente para a conservação da natureza - unidades de conservação de proteção integral. Os Povos da Floresta, por exemplo, por manterem uma estreita relação com a natureza, continuariam vivendo em seus territórios tradicionais e seriam apoiados a manter essa relação sustentável com o meio ambiente. Com essa união da agenda social com a ambiental seriam criadas as reservas extrativistas, reservas de desenvolvimento sustentável etc. - unidades de conservação de uso sustentável -, categorias de unidades de conservação cujo grande triunfo foi ofertar modelos de conservação da natureza que não excluía mais o ser humano e sim, que procuravam qualificar melhor a forma de uso dos recursos naturais que ali seriam desenvolvidos (PARANHOS FALEIRO, 2005).

Apesar do apelo social dessas iniciativas, poucos povos indígenas procuraram estreitar sua relação com as unidades de conservação e a agenda ambiental. Notadamente, foram apenas aqueles que, na época, eram considerados povos tradicionais e que, mais tarde, dentro do movimento de etnogênese, passaram a ter sua identidade étnica indígena reconhecida. Segundo alguns relatos, como a legislação assegurava aos indígenas seu território tradicionalmente ocupado, não haveria motivos para ingressar naquela luta. $\mathrm{O}$ que não significou serem indiferentes, já que eram solidários aos pleitos dos outros grupos sociais. Porém, mesmo naqueles casos de sobreposição de terras indígenas e unidades de conservação, nas propostas de conservação de recursos em terras indígenas ou na criação de categorias de territórios híbridos - como a Reserva Indígena de Recursos Naturais proposta pelo Instituto Socioambiental (ISA), por exemplo, que reunia objetivos étnicos com ambientais - não despertou interesse nos indigenistas. Pois, por um lado, persistia um consenso equivocado no meio indigenista que, assim como era feito com os títulos de propriedade, a homologação de uma terra indígena anularia a unidade de conservação. Leitura superada há pouco mais de uma década (PARANHOS FALEIRO, 2005; 2012).

Por outro lado, havia uma grande preocupação da academia e dos indigenistas em dissociar o índio como parte da natureza. Até então, o índio era considerado como ente natural, ou seja, equivalente aos animais e as árvores. Afinal, a disciplinarização do campo era uma tentativa de subordinar o índio ao Estado. Porém, ela era justificada pelo humanismo que, ao adotar a pacificação - subordinação - tutela, opunha-se ao extermínio daqueles nativos que prejudicavam o crescimento da economia. Esse esforço da academia e dos indigenistas em desconstruir o índio como parte da natureza e reconstruí-lo como humano que necessita da natureza aonde tradicionalmente vivia para continuar a ser índio - mais humano e menos natural - foi um dos argumentos mais empreendidos na segunda metade do Século XX. Antes disso, não raro, o Estado brasileiro criava Parques Nacionais para abrigar indígenas, já que estes pertenciam à mesma categoria das árvores e dos animais selvagens (PARANHOS FALEIRO, 2005; 2012). 
Todavia, o esforço em reconstruir o lugar do índio diante da natureza e a priorização da identificação das terras indígenas promoveu o distanciamento da agenda ambiental e indigenista. De um lado, os indigenistas acusavam os ambientalistas de criar unidades de conservação em terras indígenas, e os ambientalistas acusavam os índios de não serem índios e sim, aproveitadores que queriam extrair recursos das unidades de conservação. Tais argumentos distanciavam-se dos contextos históricos que facultaram a existência de alguns poucos casos que eram costumeiramente citados como exemplos. No entanto, enquanto ambientalistas e indigenistas degladiavam-se nos gabinetes, índios necessitavam de apoio na gestão de territórios finitos e insuficientes para o seu sustento nos moldes tradicionais. A combinação desta demanda com a superação dos $12 \%$ do território nacional identificado como terra indígena e a conquista da autonomia dos índigenas sobre sua representação, fizeram com que a agenda ambiental fosse pautada pelo movimento indígena apenas nas últimas duas décadas (PARANHOS FALEIRO, 2005; 2012).

Curiosamente, enquanto o movimento indigenista brasileiro buscava desvincular os índios das agendas ambientais, em outros países havia um esforço de alguns povos indígenas em associarem-se com a agenda ambiental. Pois, diferente do caso brasileiro, muitos países não possuíam uma política de reconhecimento de territórios adequada à realidade indígena e outros países criavam unidades de conservação para abrigar as etnias por considerá-las como sendo parte da natureza. Além disso, como a grande maioria dos grupos estava subsumida em categorias de campesinato que eram assistidas por extensionistas e ambientalistas desde os anos setenta, a conservação da natureza e o uso sustentável eram temas que faziam parte de sua realidade. Porém, como nos diz Oviedo (2004), isso não significa dizer que eles desejavam viver em unidades de conservação que restringiam seu modo de vida e sim, acrescento eu, que muitos deles não tiveram outra opção.

Entretanto, coincidentemente, naqueles países aonde unidades de conservação foram criadas em territórios indígenas, tanto por considerar os índios como parte da natureza, quanto por ser a unidade de conservação a única forma de proteger os recursos naturais que eles necessitavam, os índios e as agências ambientais parecem ter empreendido esforços para assegurar a permanência dos primeiros nessas unidades. Aparentemente, essa convivência com a agenda ambiental contribuiu para que índios de diferentes partes do mundo aproximassem dos fóruns ambientais e, em especial, do debate a respeito do acesso ao conhecimento tradicional. Pois, após a conclusão das rodadas de negociação da Organização Mundial do Comércio (OMC) terem estabelecido um regime de patentes desfavorável aos povos indígenas, às lideranças indígenas andinas e de outras partes do mundo incluíram na pauta da Convenção da Diversidade Biológica (CDB) a discussão de uma regulação específica para o conhecimento tradicional. Esta busca de alternativas para o impasse gerado pela $\mathrm{OMC}$ tem mobilizado os índios de muitas partes do mundo em torno da $\mathrm{CDB}$ e, mais recentemente, as lideranças de índios brasileiros também passaram a somar este debate.

Muito embora os índios brasileiros tenham sido mais tímidos na agenda ambiental até há poucos anos atrás ressalvadas as participações de Paulinho Paiacã, Raoni e David Kopenawa no contexto da Reunião do Rio, em 1992 -, também devemos reconhecer o empenho contínuo de outras lideranças indígenas brasileiras - faço menção aqui a Jorge Terena - que, há mais de vinte anos, já se dedicava a introduzir a agenda ambiental na pauta de reivindicações 
indígenas. Situação que tende a ser superada em um curto espaço de tempo, já que, nos últimos anos, as lideranças indígenas brasileiras têm estreitado seu discurso com a agenda ambiental e, como no caso do GEF Indígena, estão declarando que suas terras também são importantes para a conservação do meio ambiente, desde que manejadas pelo modo tradicional de cada etnia. Ou seja, não estão falando apenas da conservação de um território em termos de tamanho de área, mas sim, do uso que se faz dele.

Em outras palavras, independente dos motivos que retardaram o ingresso do movimento indígena nos debates internacionais, o esforço que eles têm feito nas últimas décadas aponta para um futuro promissor neste quesito. Pois, além de assumirem um discurso mais autônomo, elaborado e articulado, as lideranças têm participado mais ativamente da representação política, técnica e administrativa nos fóruns que lhes são mais estratégicos. Postura que coincide coma priorização da temática indígena pelos organismos internacionais - a pressão para os países aderirem a Convenção 169 da Organização Internacional do Trabalho e a Declaração das Nações Unidas sobre os Direitos dos Povos Indígenas etc. -, com a priorização destes povos na aplicação de recursos - combate à pobreza, conservação ambiental-e com as ações das organizações não governamentais - The Nature Conservancy (TNC), Conservação Internacional (CI) dentre outras.

\section{REPRESENTAÇÃO INDIGENISTA VERSUS INDÍGENA: ONDE A INTERVENÇÃO} ACONTECE

A história da conquista dos povos indígenas foi marcada pelo esforço dos Estados nacionais em dominá-los e pela luta dos primeiros pela sobrevivência. Em que pese às consequências funestas desse processo, em paralelo ao esforço de sobreviver, hoje observamos que os povos indígenas buscam cada vez mais melhorar suas condições de vida. Para isso, suas lideranças têm buscado participar ativamente dos fóruns estatais e das agendas nacionais e internacionais, onde procuram assegurar direitos e obter apoio para os projetos que precisam ser desenvolvidos nas aldeias. Por mais que possamos criticar o desempenho de algumas lideranças, pensando ser este um processo maior que as pessoas que ocupam postos de representação, não poderíamos ser tão prepotentes ao ponto de dizer que os povos indígenas não deveriam agir dessa ou daquela forma. Afinal, o domínio da participação política não se dá apenas na preparação teórica e ideológica, mas, principalmente, no exercício constante, reflexivo e crítico de seu desempenho na participação política. Ou seja, só se aprende a participar participando.

Aparentemente, a condição legal de reconhecimento territorial influenciou o estabelecimento de prioridades dos indígenas em cada país e também, contribuiu com a formação do movimento indígena. Pois, enquanto os indígenas andinos estabeleceram organizações representativas próprias, autônomas e atuantes, no Brasil, algo semelhante ocorreria apenas nas últimas décadas. Em parte, devemos isso à condição diferenciada do indígena e a atribuição de uma "pureza" idílica que, historicamente, lhes cotejamos na literatura, elementos que fizeram com que a sociedade brasileira os tratasse como incapazes que precisavam ser: tutelados, controlados e nacionalizados. Esse tratamento ambíguo - cuidar e controlar - expropriou o índio de recursos, territórios e do exercício da cidadania. 
Desde o Brasil colonial, os índios têm sido representados por não indígenas que, não raro, elegiam alguns indivíduos como provas vivas de sua legitimidade. Se no passado tais provas eram quase que ilustrativas (ARINOS, 1976), maisrecentemente, eram escolhidos índios cujo discurso “afinava” com as agendas defendidas pelos indigenistas. Como nos lembra Gallois (2004), a organização política tradicional dos grupos indígenas no Brasil costumava ser uma extensão das redes de sociabilidade típicas de sua cultura, entre elas: a família. Certamente, essa rede permitiu que, por muito tempo, alguns indivíduos fossem eleitos como legítimos porta-vozes de toda uma etnia que, sequer, dedicavase a acompanhar os acontecimentos políticos que os afetavam. Atualmente, segundo algumas lideranças, esse tipo de representante indígena que falava em nome da etnia e que, na realidade, cuidava apenas dos interesses de sua "família", não costuma ser aceito pelos índios das aldeias. Muito embora, muitas dessas lideranças chamadas acintosamente pelos indígenas de "representantes de suas famílias" continuam a ser aceitas pelo Estado - seja por conveniência ou desconhecimento - como representantes legítimos da coletividade.

Como nos lembra Farage a respeito do chefe indígena em Roraima e na Guiana:

'tanto portugueses como holandeses investiram politicamente na figura de um chefe indígena que, para emprestar o mote de Pierre Clastres, se não existisse, teria sido inventado. Encontrar o chefe parece assim não ter sido apenas, como troçou Malinowski, tarefa de que se encarregaram os primeiros antropólogos, mas, de modo mais trágico, um pressuposto mesmo da tarefa de colonizar." (FARAGE, 1986: 343)

A função de chefe similar aquele do ocidente inexistia na cultura de muitos povos indígenas do Brasil. Por isso, sem sombra de dúvida, sua escolha teria sido um instrumento de diálogo dos não índios com os índios e uma forma de controlar os últimos. Transportando-nos para um período mais recente, esse papel não precisaria mais ser desempenhado pelo chefe, já que a liderança, familiar ou não, garantiria legalidade necessária para a agenda indigenista.

Apesar desse controle do índio realizado pela tutela indigenista, independente desta ser estatal, religiosa ou militante, não podemos negar que havia indigenistas convictos de estarem fazendo o melhor para os índios. Afinal, na segunda metade do Século passado, predominava na academia uma exacerbada defesa da manutenção dos índios em seu estado cultural diferenciado, ou seja, alheios à influência não indígena. Na militância, estivesse ela situada no Estado, nos órgãos eclesiásticos ou nas organizações não governamentais, prevalecia à desconfiança dos governos de direita e a conviç̧ão na falta de compromissos destes com os índios. Talvez por isso, ao menos para eles, uma orientação ainda que controlada das lideranças indígenas fosse justificada.

Não obstante este zelo indigenista possa ter contribuído para afastar os índios de uma representação política mais autônoma, por si só, esta forma de controle não poderia ser a única responsável pelo distanciamento do índio e da agenda ambiental. Afinal, nos anos oitenta, as sobreposições entre unidades de conservação e terras indígenas havia criado um antagonismo entre o movimento indígena e ambiental. Isso fez com que, ao menos no Brasil, índios, indigenistas e ambientalistas, entrassem em disputa pela prevalência de uma categoria em detrimento da outra. Além disso, a falta de índios preparados para gerir recursos oriundos de projetos ambientais, fez com que organizações não 
governamentais indigenistas captassem esses recursos que, em tese, foram aplicados nas aldeias.

Esse papel ambíguo da tutela indigenista persiste em muitos tutores habituais e entre indígenas. De um lado, habituados com o recurso sem burocracia, muitos grupos que não tem prática com projetos, acabam contando com apoio de não indígenas para gerir a burocracia que vem por trás da aplicação dos recursos. Algo normal até que seja criada uma expertise indígena sobre o tema. De outro lado, instituições mais idôneas trabalham para viabilizar a aplicação desses recursos e, na medida do possível, capacitam os índios para trabalharem com a burocracia dos projetos. No entanto, ao menos pudemos observar isso no GEF Indígena, tanto no Estado quanto nas organizações não governamentais, persistem "pessoas" que trabalham em "causa própria" e que, não raro, explicitam a defesa da tutela. Independente da idoneidade dessas pessoas, tais pessoas precisam estar atentas sobre suas posturas, a fim de não professarem algo análogo a ritual troca de espelhos do Século XVI, quando colonizadores portugueses davam aos índios bugigangas em troca de madeira e drogas dos sertões que valiam muito mais.

Além dessa reserva de conhecimento, em nome da defesa dos índios, alguns tutores indigenistas exerciam uma vigilância ideológica das lideranças indígenas. Segundo relatos de alguns líderes indígenas, até os anos noventa, qualquer liderança que dialogasse com o governo, acabava alijada do movimento por divergirem da orientação indigenista. Porém, quando a maioria das lideranças partiu para o diálogo, os indigenistas não tiveram como controlar e, após revisarem seu papel, assumiram o espaço de apoio ao movimento indígena. Com isso, o movimento indígena começou a substituir o protagonismo desempenhado pela tutela indigenista, etambém, passaram a ocupar novos fóruns institucionais, a dialogar com diferentes organizações e a articular em vários níveis a representação do movimento - da aldeia até Articulação dos Povos Indígenas do Brasil (APIB).

Segundo alguns relatos, houve um grande investimento dos indigenistas em constranger as Comemorações dos 500 anos de Descoberta do Brasil. Independente dos resultados alcançados, após as comemorações, o movimento indigenista começou a ser definitivamente indígena. Aproveitando as edições do Acampamento Terra Livre - Brasil Indígena, reuniões da Carteira Indígena, GEF Indígena e de outros projetos ambientais, a Coordenação das Organizações Indígenas da Amazônia Brasileira (COIAB) e a Articulação dos Povos Indígenas do Nordeste, Minas Gerais e Espírito Santo (APOINME) passaram a estimular as lideranças de outras regiões do país a estruturar o movimento em nível regional. Com isso, nasceram a Articulação dos Povos Indígenas do Sul (ARPINSUL), a Articulação dos Povos Indígenas do Sudeste (ARPINSUDESTE), a Articulação dos Povos Indígenas do Pantanal e Região (ARPIPAN) e a Grande Assembleia do povo Guarani (ATY GUASSÚ).

Paralelamente, após a Rio+10, realizada em Johanesburgo, África do Sul, em 2002, as agendas internacionais de meio ambiente incorporaram o combate à pobreza com mais veemência dentro de suas prioridades. Seguindo esta tendência, The Nature Conservancy (TNC), organização não governamental ambientalista, passou a apoiar as organizações indígenas e projetos ambientais em terras indígenas. Nesse contexto, as experiências acumuladas pelas organizações indígenas, instituições públicas, privadas, não governamentais e internacionais, e o empenho de algumas lideranças indígenas, contribuíram com projetos que promoveram o ingresso dos povos indígenas na agenda ambiental 
- Carteira Indígena do Ministério do Meio Ambiente, Programa Rio Negro e Xingu do Instituto Socioambiental, Programa Wajäpi do Instituto de Pesquisa e Formação Indígena (IEPE), Programas de capacitação do Instituto Internacional de Educação do Brasil (IEB), GEF Indígena do Ministério do Meio Ambiente/Fundação Nacional do Índio etc.

Contudo, um novo cenário ainda está por ser descortinado. Após uma trajetória de conquista de sua autonomia política, os povos indígenas do Brasil conseguiram afirmar seus direitos territoriais, culturais e sociais. Nesta luta, eles conseguiram converter as formas de controle - pequenas áreas, assimilação, assistência, integração, tutela etc. - em meios de vida - território adequado, políticas que respeitam a diversidade cultural, representação própria e assim por diante. Para isso, contaram com parceiros que, bem intencionados ou não, também aprenderam a respeitá-los e, de certa forma, contribuíram com a autonomia política que as organizações indígenas possuem hoje. Porém, muito embora venham superando a tutela indigenista estatal, religiosa ou de organizações não governamentais, ainda assim, o descompasso entre lideranças bem preparadas e aquelas que limitam sua atuação na busca de melhores condições de vida, tem ofertado porta-vozes coniventes com interesses empresariais e políticos.

Segundo alguns relatos, a perniciosa prática de eleição de representantes indígenas afinados com a agenda de algumas instituições tuteladoras têm esvaziado os debates indígenas no âmbito da Comissão Nacional de Política Indigenista (CNPI). Curiosamente, esta Comissão criada pelo ex-presidente Luiz Inácio Lula da Silva que, seguindo os princípios democráticos do Partido dos Trabalhadores (PT), deveria dar voz aos índios, possui poucos representantes indígenas que também estão à frente do movimento indígena regional e nacional, o que nos impõem uma questão: o Estado brasileiro estaria congelado no tempo, enquanto indígenas e indigenistas não estatais estão avançando rumo ao: "Brasil, Um país de todos"? - bordão do Governo do Partido dos Trabalhadores.

Evidentemente, acompanhandoosavançosdomovimentoindígenaesuainserçãoemespaçosinstitucionalizados pelo Estado, ao levar demandas para esses fóruns, como contrapartida, eles acabam recebendo demandas de outros setores da sociedade. Por este motivo, agendas de desenvolvimento, de meio ambiente, de comércio e de direitos, acabam gerando uma intervenção na vida das aldeias, ainda que perceptível apenas em médio prazo. Intervenção por contrapartida que, nas últimas décadas, tem sido convenientemente explorada pelos governos do Brasil nas agendas de desenvolvimento - construção de barragens, estradas, exploração mineral, extração de madeira e outros recursos naturais. Talvez por isso, o aparente descompasso do governo atual pareça persistir. Afinal, é muito mais fácil negociar com um governo que, diante da diversidade de zelosos indigenistas de plantão - ora trabalhando no movimento, ora no Estado-, consegue acessar os recursos situados em terras indígenas.

O descortinar desta aurora do movimento indígena impõe que respeitemos esse esforço de povos tão expropriados. Para isso, faz-se necessário eliminar quaisquer formas de tutela do índio e de suas organizações. Caso contrário, continuaremos a praticar a ambiguidade da colonização lusitana do Brasil, onde as leis promovem a cidadania enquanto os "espelhinhos" extraem a riqueza. 


\section{BIBLIOGRAFIA}

CAMPOS, Ciro; PINTO, Flávia; BARBOSA, Reinaldo Imbrozio, 2008. O “Lavrado” de Roraima: Importância Biológica, Desenvolvimento e Conservação na maior Savana do Bioma Amazônia - Diagnóstico. Boa Vista: INPA.

FARAGE, Nádia, 1986. As Muralhas dos Sertões: os povos indígenas no Rio Branco e a colonização. Dissertação de Mestrado. Campinas: Unicamp.

FRANCO, Afonso Arinos de Melo, 1976. O Índio Brasileiro e a Revolução Francesa: as origens brasileiras da teoria da bondade natural. 2a Ed. Rio de Janeiro: J. Olympio; Brasília: INL.

GALLOIS, Dominique Tilkin, 2004. Terras ocupadas? Territórios? Territorialidades?. IN: RICARDO, Fany. (Org.). Terras Indígenas \& Unidades de Conservação da Natureza. 1 ed. São Paulo: Instituto Socioambiental. PP 37-41.

GOZZI, Gustavo, 1998. Estado Contemporâneo. IN BOBBIO, N., MATTEUCCI, N., PASQUINO, G. Dicionário de Política. Brasília, EdUnB, $11^{\mathrm{a}} \mathrm{Ed}$.

LIMA, Antonio Carlos de Souza, 1995. Um grande cerco de paz: poder tutelar, indianidade e formação do Estado no Brasil. Petrópolis, RJ: Vozes.

MELATTI, Júlio Cezar, 1987. Índios do Brasil. São Paulo: Editora Hucitec.

OVIEDO, Gonzalo, 2004. Áreas Protegidas y Pueblos Indígenas. IN Arguedas, M.E. CASTAÑO, B. L., RODRÍGUEZ, J. M. (Editores). Lineamientos y Herramientas para un Manejo Creativo de las Áreas Protegidas. San José: Organización para Estudios Tropicales (OET)/ Programa de Políticas y Ciencias Ambientales.

PARANHOSFALEIRO, Rodrigo, 2009. La Mensura de la Maldad: autonomía, tutelay dominación, nuevas artimañas del control étnico (mimeo). Trabalho aceito pelo GT 12: Indigenismos e Políticas Indigenistas nas Américas. Para uma análise comparativa das relações entre povos indígenas e Estados nos Séculos XX e XXI. Coordenado por Antonio Carlos Souza Lima, Guillaume Boccara, Claudia Briones. VIII Reunión de Antropologia del Mercosur: Diversidad y Poder em América Latina. Buenos Aires.

PARANHOS FALEIRO, Rodrigo, 2012. Náwa, índios ou ribeirinhos? Quando os órgãos públicos entram em conflito. IN BAINES, Stephen Grant, SILVA, Cristhian Teófilo do, FLEISCHER, David Ivan, PARANHOS FALEIRO, Rodrigo. Variações Interétnicas: etnicidade, conflitos e transformações. Brasília: IBAMA; UnB/CEPPAC; IEB.

PARANHOS FALEIRO, Rodrigo, 2005. Unidade de conservação versus terra indígena, um Estado em conflito: estudo da influência da pessoa na gestão pública. Dissertação de Mestrado em Antropologia. Orientador Paul E. Little. Brasília: Universidade de Brasília.

RIBEIRO, Darcy, 1970. Os índios e a civilização: a integração das populações indígenas no Brasil moderno. Rio de 
Janeiro: Civilização Brasileira.

TIVEY, Leonard (org.), 1981. El Estado Nación. Barcelona: Ediciones Penísula. 